\title{
MicroRNA expression profile predicts prognosis of pediatric adrenocortical tumors
}

\author{
Luciana Veronez ${ }^{1}$, Paola Fedatto ${ }^{1}$, Carolina Corrêa ${ }^{1}$, Régia Lira ${ }^{2}$, Mirella Baroni ${ }^{1}$, \\ Keteryne Silva ${ }^{3}$, Paula Santos ${ }^{4}$, David Antonio ${ }^{5}$, Rosane Queiroz ${ }^{6}$, Sonir Antonini ${ }^{7}$, Silvio \\ Tucci Jr ${ }^{1}$, Luciano Neder ${ }^{8}$, Jose Yunes ${ }^{9}$, Silvia Brandalise ${ }^{9}$, Rodrigo Panepucci ${ }^{1}$, Luiz \\ Gonzaga Tone ${ }^{1}$, and Carlos Scrideli ${ }^{10}$ \\ ${ }^{1}$ Universidade de Sao Paulo Faculdade de Medicina de Ribeirao Preto \\ ${ }^{2}$ Faculty of Medicine of Ribeirão Preto, University of São Paulo \\ ${ }^{3}$ Universidade de São Paulo Faculdade de Medicina de Ribeirão Preto \\ ${ }^{4}$ University of Sao Paulo Faculty of Philosophy Letters and Human Sciences \\ ${ }^{5}$ Seven Bridges Biotech Consulting \\ ${ }^{6}$ Faculdade de Medicina de Ribeirão Preto, Universidade de Sao Paulo \\ ${ }^{7}$ School of Medicine of Ribeirão Preto \\ ${ }^{8}$ Faculty of Medicine of Ribeirão Preto, University of São Paulo, Brazil. \\ ${ }^{9}$ Centro Infantil Boldrini \\ ${ }^{10}$ Universidade de São Paulo (USP)
}

October 16, 2021

\begin{abstract}
Pediatric adrenocortical tumors (ACT) are rare aggressive neoplasms with heterogeneous prognosis. Despite extensive efforts, identifying reliable prognostic factors for pediatric patients with ACT remains a challenge. MicroRNA (miRNA) signatures have been associated with cancer diagnosis, treatment response, and prognosis of several types of cancer. However, the role of miRNAs has been poorly explored in pediatric ACT. In this study, we performed miRNA microarray profiling on a cohort of 37 pediatric ACT and nine non-neoplastic adrenal (NNA) samples and evaluated the prognostic significance of abnormally expressed miRNAs using Kaplan-Meier plots, log-rank test and Cox regression analysis. We identified a total of 98 abnormally expressed miRNAs, which expression profile discriminated ACT from NNAs. Among the 98 deregulated miRNAs, 17 presented significant associations with patients' survival. In addition, higher expression levels of hsa-miR-630, -139-3p, -125a-3p, -574-5p, $-596,-564,-1321$, and -423-5p and lower expression levels of hsa-miR-377-3p, -126-3p, -410, -136-3p, -29b-3p, -29a-3p, -337-5p, 143-3p, and 140-5p were significantly associated with poor prognosis, tumor relapse, and/or death. Importantly, the expression profile of these 17 miRNAs stratified patients into two groups of ACTs with different clinical outcomes. Although some individual miRNAs exhibit potential prognostic values in ACTs, only the 17 miRNA-based expression clustering was considered an independent prognostic factor for five-year event-free survival (EFS) compared to other clinicopathological features. In conclusion, our study reports for the first time associations between miRNA profiles and childhood ACT prognosis, providing evidence that miRNAs could be useful biomarkers to discriminate patients with favorable and unfavorable clinical outcomes.
\end{abstract}

\section{Hosted file}

Manuscript PBC 2021.docx available at https://authorea.com/users/441415/articles/541916microrna-expression-profile-predicts-prognosis-of-pediatric-adrenocortical-tumors

\section{Hosted file}


TABLE 1.docx available at https://authorea.com/users/441415/articles/541916-micrornaexpression-profile-predicts-prognosis-of-pediatric-adrenocortical-tumors

\section{Hosted file}

TABLE 2.docx available at https://authorea.com/users/441415/articles/541916-micrornaexpression-profile-predicts-prognosis-of-pediatric-adrenocortical-tumors

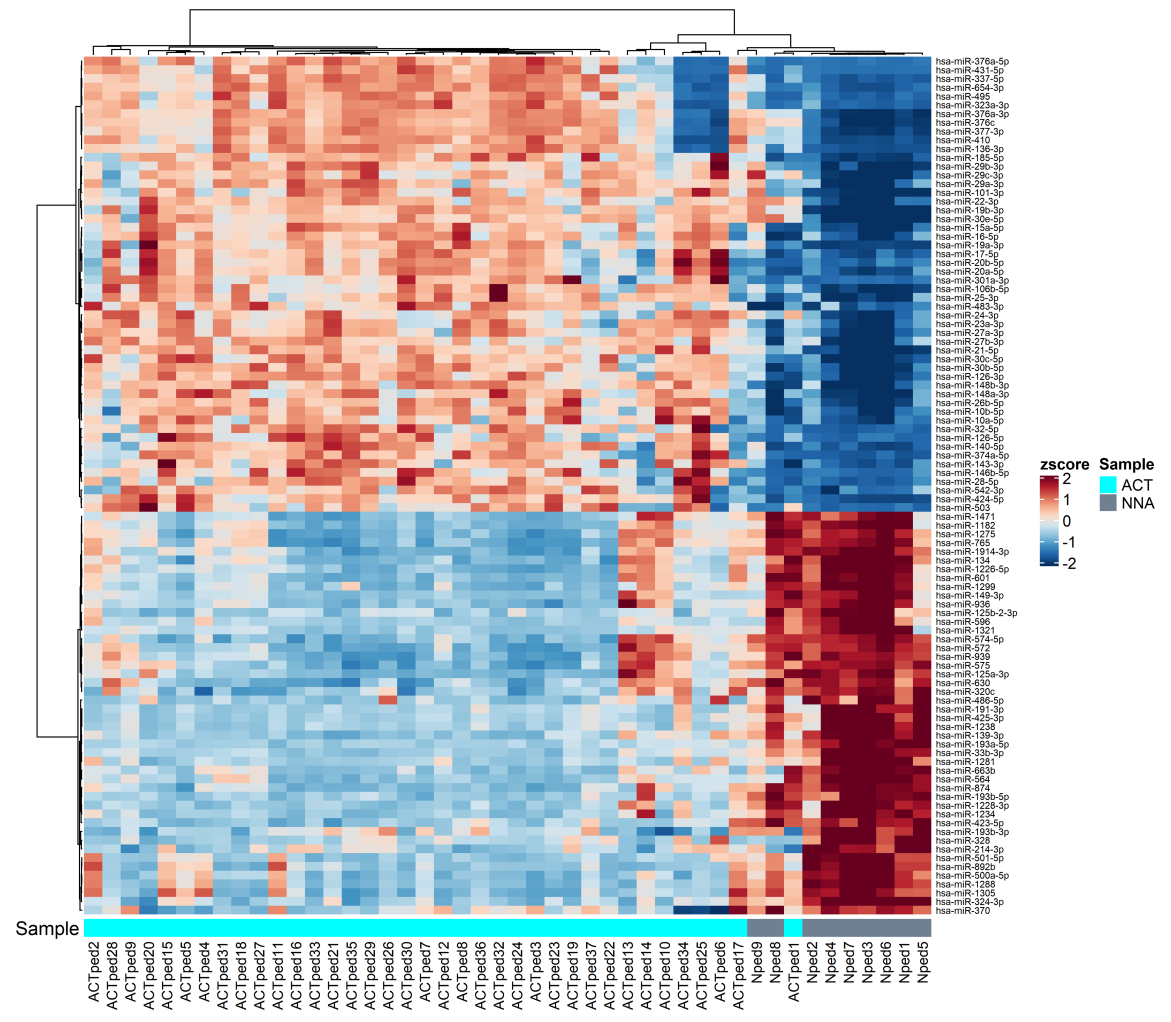


A
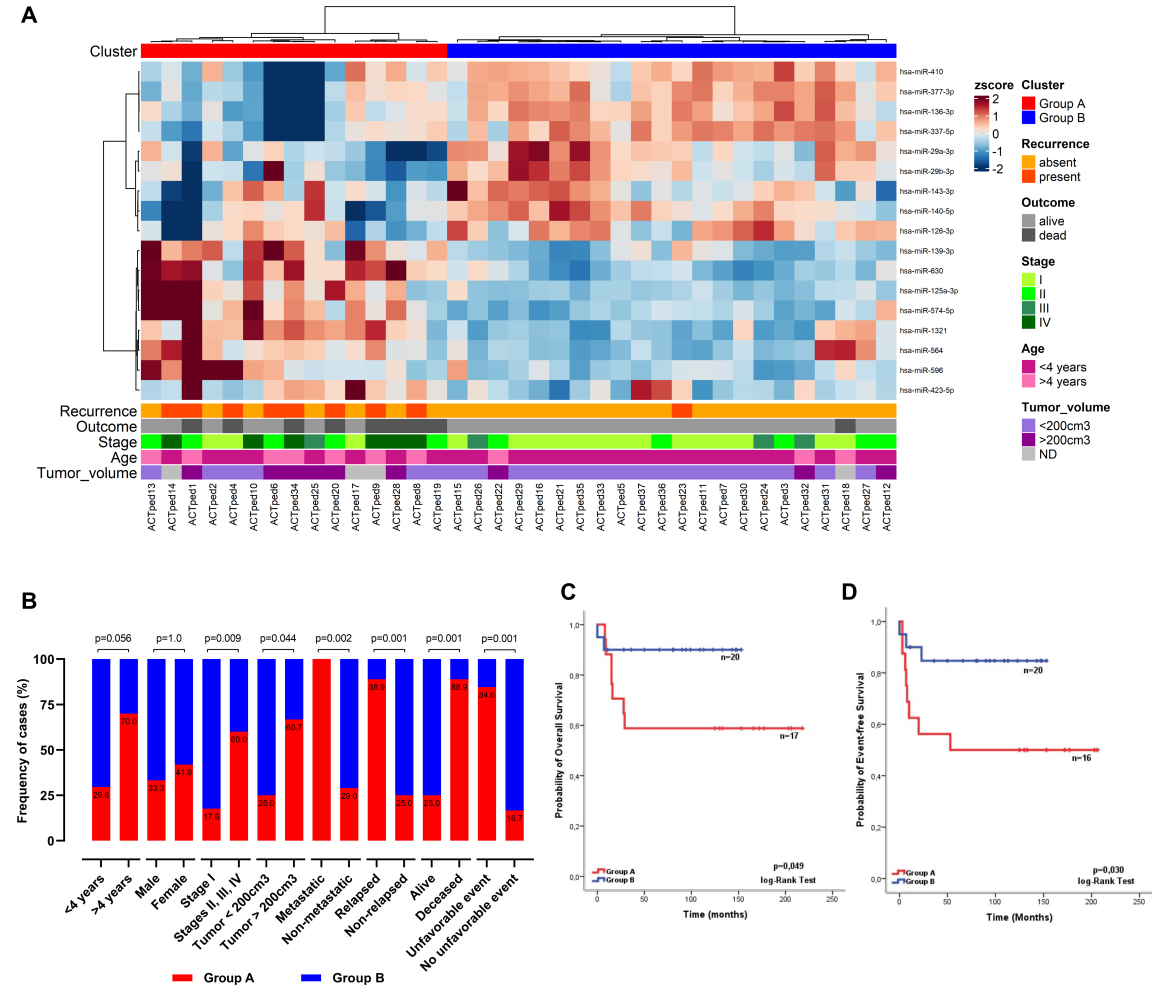


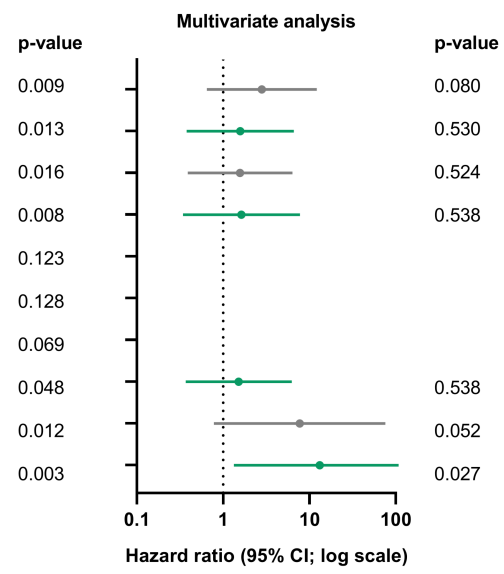

B

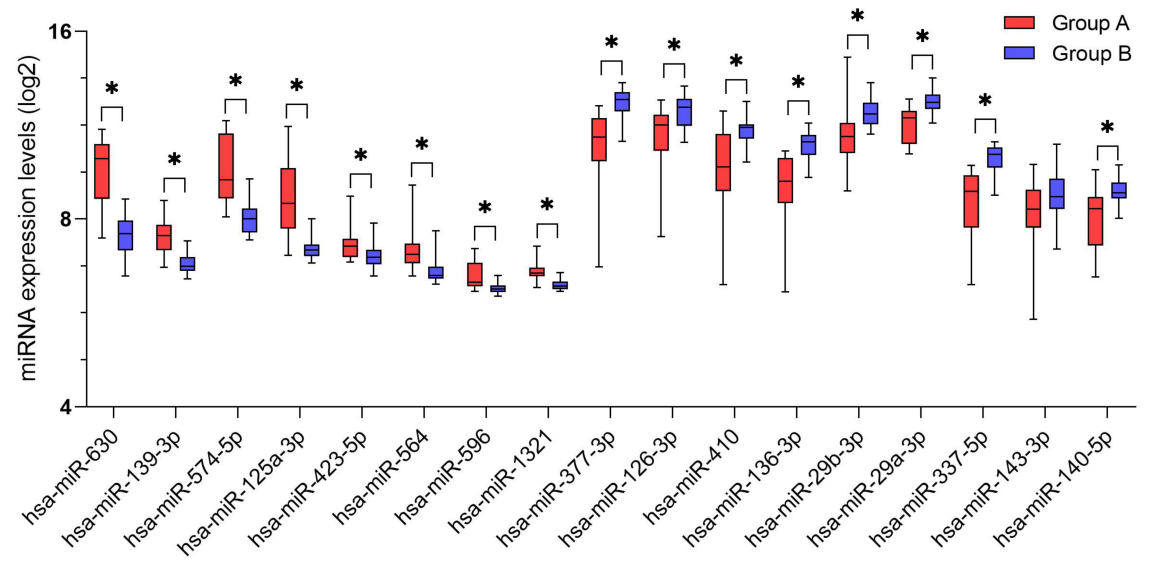

C

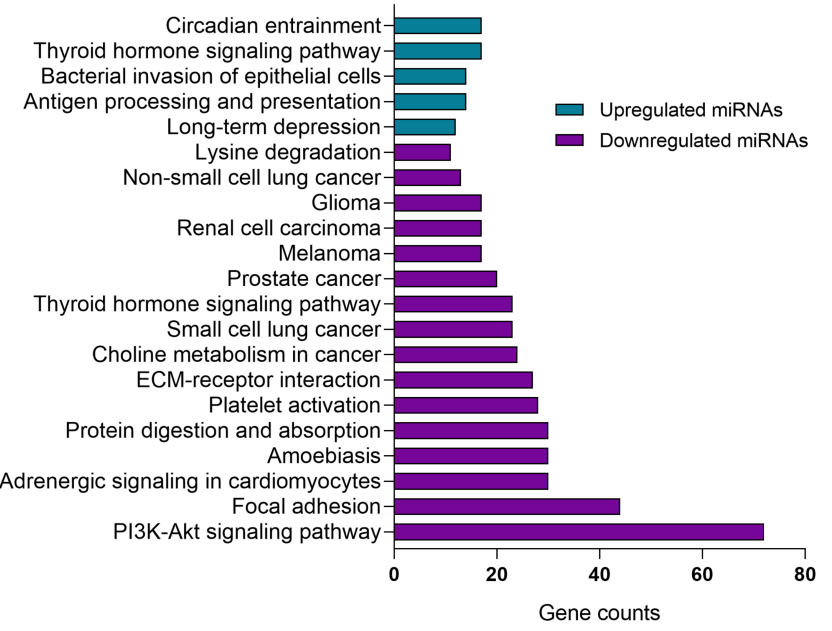

